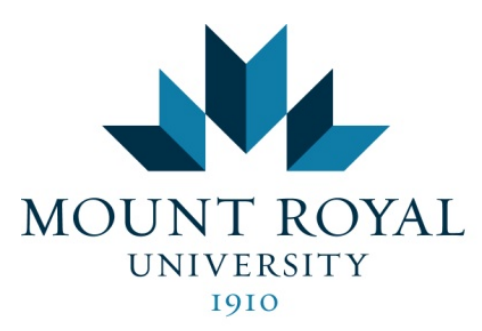

Department of Education and Schooling

Mount Royal Undergraduate Education Review

Volume 1(1)

Spring 2014

\title{
Inquiry based learning and technology, negative or positive?
}

Tory Hilton, Mount Royal University

\begin{abstract}
I completed this research study because I wanted to find out if assistive technologies in the elementary classroom are helping students with attention deficit disorder (ADD), attention deficit, hyperactivity disorder (ADHD) and anxiety issues to succeed, and what other people’s perspectives on the uses of those technologies were. An online survey was sent out using social media to reach parents, students, and teachers in order to get their perspectives on this question. I found that $45 \%$ of the people surveyed indicated that assistive technologies, in their opinion, are helping those students, while $13 \%$ said that they are not helping students. I also found that $72 \%$ of the people surveyed stated that, in their opinion, the use of these technologies is not giving students an unfair advantage, but rather leveling out the playing field, while $5 \%$ said that they believe that the use of digital technologies is giving students an unfair advantage. Based on my findings, I would say that these assistive technologies are benefiting students with ADD, ADHD, or anxiety issues, and that it does not give them an unfair advantage over other students, it just helps them to have the same chance at success as the others.
\end{abstract}




\section{Introduction}

I wanted to inquire about how digital technologies can assist the learning and growth of students with attention deficit disorder (ADD), attention deficit, and hyperactivity disorder ADHD, anxiety, and learning disabilities within the elementary classroom because of my personal connection to this issue. I have both ADD and anxiety, and I have been exposed to some digital technologies to help me be successful in learning. The range of technologies is growing rapidly, and so I wanted to investigate what new technologies were available to help the elementary students that I will be working with in the future. I know first hand, how important assistive technologies can be to success in learning, and I want to give those opportunities to the young students I will work with in the future. By conducting this study, I personally learned more about what assistive technologies are available to students with varying needs, and I gained insight into other people's opinions on the use of these technologies in the elementary classrooms.

\section{Background}

There has been a great deal of research conducted on the use of assistive technologies in the classroom helping students with ADD and ADHD. Upon my initial research into this topic, I came across an article that talked about the values of using assistive technologies within the classroom (Cobb, 2011). This article first defined a few of the many definitions of what assistive technologies can be classified as. Cobb (2011) states that there are a variety of definitions for what assistive technologies can be, and they are the following:

“(a) Any item, piece of equipment, or product system, whether acquired commercially, modified, or customized, that is used to increase, maintain, or improve functional capabilities of individuals with disabilities. (b) devices and software designed specifically 
for those with learning or physical disabilities. And (c) AT has powerful tools that support physically challenged students with equal opportunities to more fully participate in the teaching-learning process.” (p. 47)

Cobb (2011) also states that assistive technologies can be of benefit to students with learning disabilities because they can provide them with increased self-confidence as a student as well as increased academic performance because of that (p. 50).

Another article that I found on this topic discussed the Play Attention Learning System, which as stated by Siglin (2000) is "a feedback-based integrated learning tool designed to increase focus, time-on-task, short-term memory, visual tracking and discriminatory tasks” (p. 122). This learning system was designed for the specific needs of students who have difficulties paying attention. Peter Freer, who invented the Play Attention system, created this application because throughout his time as an educator, he realized that educators had a lack of resources available to accommodate the needs of students who struggle with attention (Siglin, 2000, p. 122).

A third article I discovered on my question of inquiry provided an overview to the different technologies that are available to be used in the classroom to help students with different learning disabilities (Forgrave, 2002). Text-to-speech technology can help students with reading comprehension. If they struggle with decoding words and information, this technology can help them to make sense of what they are reading by listening to it (Forgrave, 2002, p. 122). There is also speech-to-text software that can help students who struggle with writing and organization skills. This software allows students to speak the words out before they are forgotten, and have them be put into text format for them automatically. 


\section{Research Context}

I conducted my research using an online survey in order to gain anonymous results. My participants were mostly university students, with some teachers, a couple parents, and a few who identified themselves as none of these categories but still participated in the survey (Figure 1). I also completed my Canadian Human Ethics Research Certificate in order to conduct my survey in a manner that put none of my participants at risk. At the beginning of the survey I clearly outlined that all results would remain anonymous, and I made sure that all of my participants were over the age of 18 so that I did not need to gain informed consent from parents or guardians.

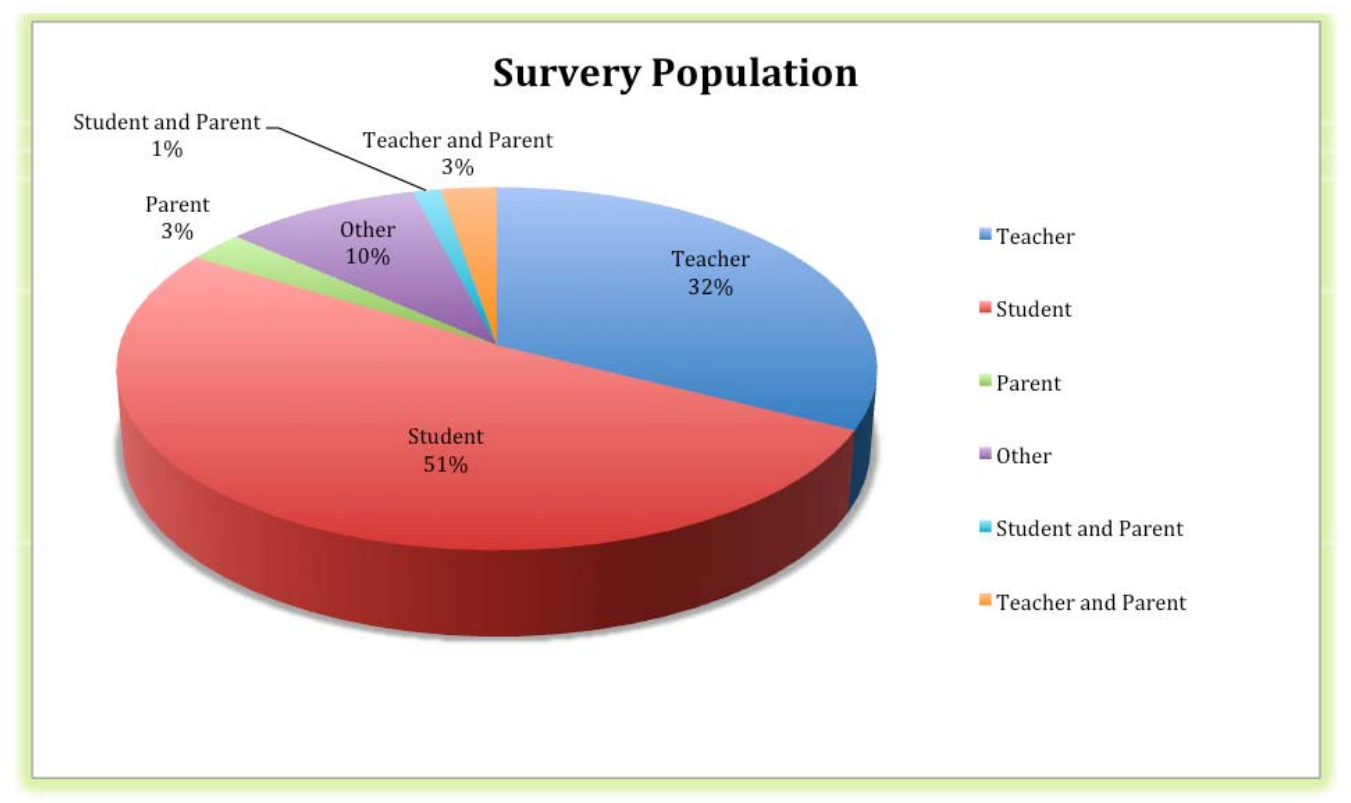

Figure 1. Demographics of survey participants

I had a total of seventy-four people complete my online survey; 51\% were university students, $32 \%$ were teachers, $10 \%$ identified themselves as others, $3 \%$ were parents, $3 \%$ were teachers and parents, and $1 \%$ were students and parents. 


\section{Methods of Investigation}

I created an online survey using Google Forms, and I sent it out to people on Facebook and Twitter. I carefully formulated eleven questions that would guide me in my research, and reached out to people who I thought might have a background or experience with the field of assistive technologies being used in the elementary classroom. I chose to use the online survey format for my research because I felt that it was the best way that I could gather anonymous results, to eliminate the chance for bias when it came to analyzing my data in Google Spreadsheets.

\section{Findings}

The first question on my survey asked participants about how comfortable they were with the resources and technologies available to them to be used in a classroom and the second question probed how comfortable they were with using those technologies to help students (Figure 2 and 3). Seventy percent of the participants answered that they were either sort of comfortable to fairly comfortable for both questions.

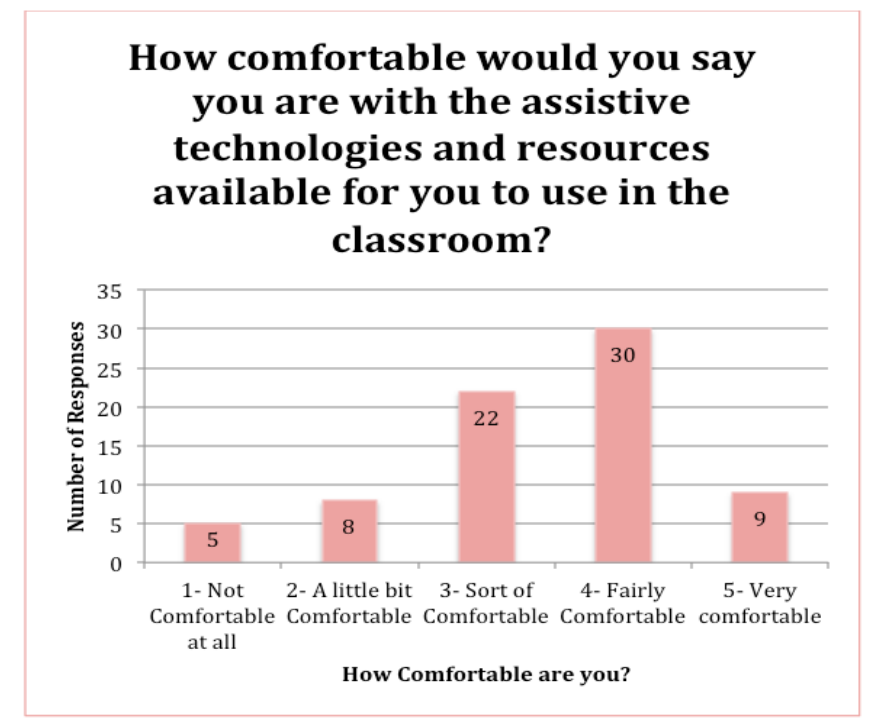

Figure 2. Comfort level with the assistive technologies and resources available for you to use in the elementary classroom 


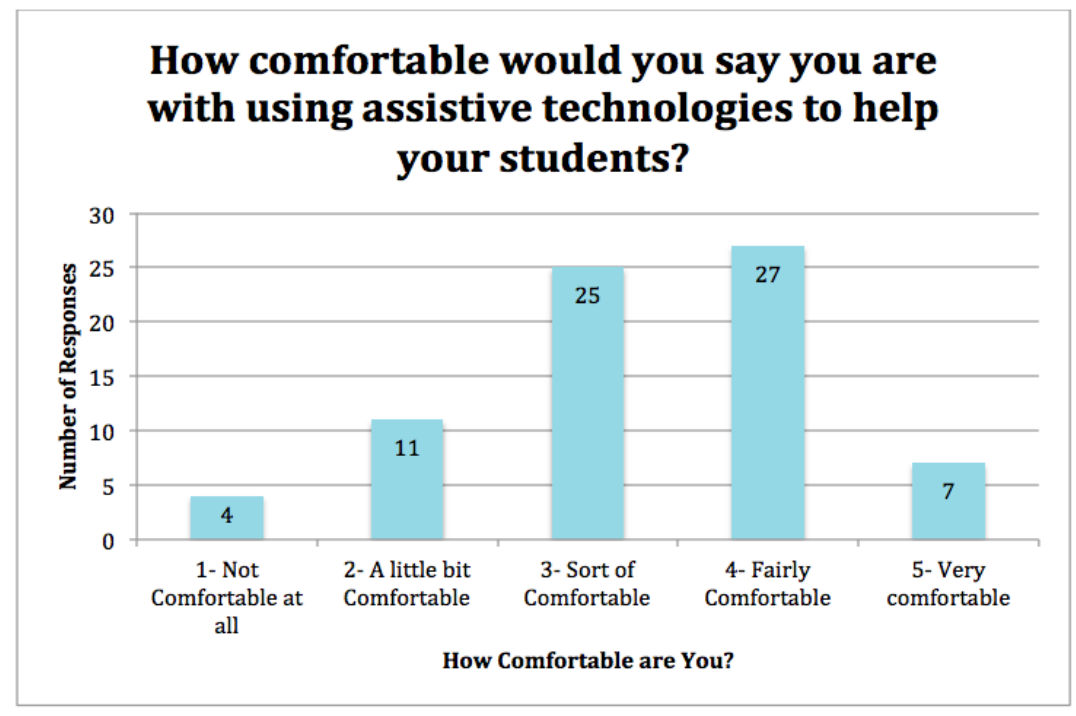

Figure 3. Comfort level with using assistive technologies to help elementary students

In Figure 2, 47\% of participants said that they felt between not comfortable at all to fairly comfortable with the assistive technologies available to them to use in the classroom, and similarly, in Figure 3, 54\% of participants said that they felt between not comfortable at all to fairly comfortable with using assistive technologies to help their students.

In Figure 4, 42\% of the participants answered that they did not know if assistive technologies in the classroom were helping students with ADD, ADHD and anxiety issues or not. To compare these results, I thought it was interesting that a similar number of participants answered very similarly on those two questions, and then a similar number of participants also did not know if the assistive technologies were helping these students. This leaves me wondering if teachers and parents are just lacking the education on the resources available to be used in elementary schools? 


\section{Do you think that technology in the classroom is helping students who have ADD, ADHD, and anxiety issues?}

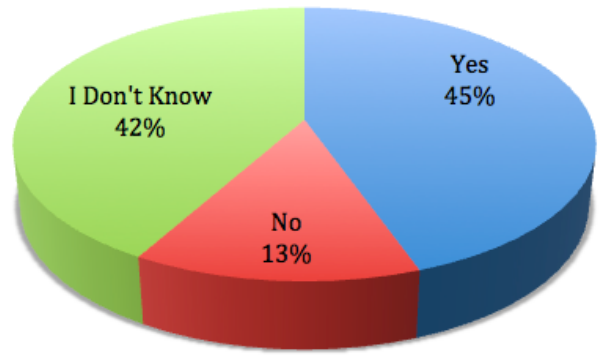

Figure 4. Ability of digital technologies in the elementary classroom is helping students who have ADD, ADHD, and anxiety issues?

Similar to the above analysis of the results, in Figure 2, 17\% of participants answered with feeling not comfortable at all to a little bit comfortable with the assistive technologies available to them to use in the classroom, and similarly, in Figure 3, 20\% of participants said that they felt between not comfortable at all to a little bit comfortable with using assistive technologies to help their students.

In Figure 5, 23\% of participants answered that they didn't know if the use of assistive technologies in the classroom were giving students an unfair advantage over the other students. Once again, these results have left me wondering if there is a lack of use and education on assistive technologies in the classroom for people to have an opinion on this question. 


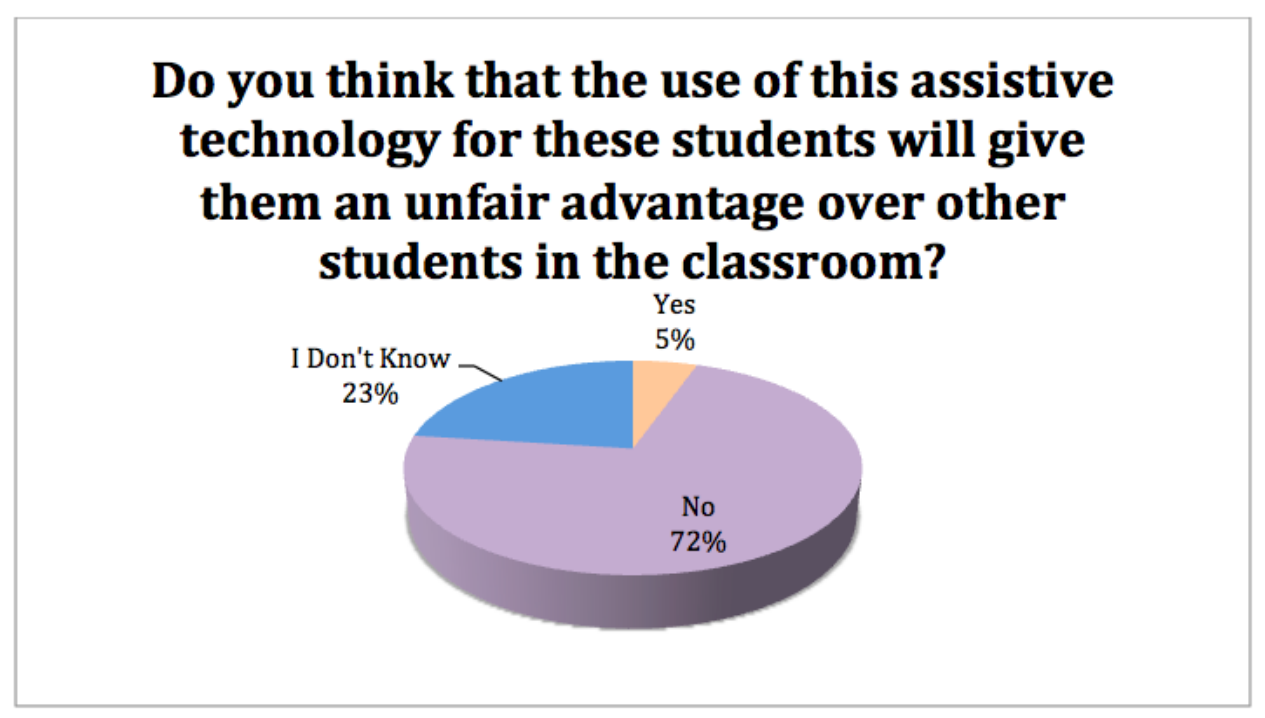

Figure 5. Do assistive technologies give students an unfair advantage over other students in the elementary classroom?

\section{Conclusions}

In conclusion, almost half of my survey participants thought that the use of assistive technology was helpful. Seventy-two percent of the participants indicated that they did not think that it gave students an unfair advantage over other students in the classroom. From my own personal experiences, I do not think that the use of assistive technologies gives the students who use them an unfair advantage over other students. Participant 3 in the survey stated that "The students will use the technology to help them with activities that they are otherwise unable to do in comparison to students without ADD.” Participant 33 in the survey indicated that "If this is something they need in order to have an equal opportunity for learning and success, it is not unfair. They are not being given this technology as a bonus; they are being given the technology because it is something they need to complete their work.”

Participants of my online survey responded about many different assistive technologies that are available to use in the elementary classroom today. I looked into four of them that I thought would be of use in my classroom, three of them I have used myself. The first assistive 
technology is Dragon Naturally Speaking (2014). It is a speech-text program that takes the words you say, and translates them into text on the computer. If a student is struggling with getting their ideas down on paper, they can use this to speak and get the ideas out, and the software will translate their words into text. Another technology that I looked into was Word Q (2011). Its main purpose is to help individuals who are struggling with writing. WordQ uses word prediction technology to suggest words that a student might be typing into documents and emails, helping with the spelling process. It also uses text-to-speech software to read back text that the user has entered, allowing for proof reading and editing. The third assistive technology that I investigated was the Read and Write Gold Software (2014) which reads electronic text from e-books, websites, and documents created in word-processing programs. The program includes voice dictation that also reads aloud what students write and helps them identify errors. This software can be helpful for students who are struggling with focusing and reading something, the software will read it back to them and they can listen to it. The last assistive technology that I looked into was the Echo Pen (2013). This pen can record speech, and is connected to a special notebook. The user of this pen and notebook can use the recordings from the pen to fill in missing blanks in notes which were made in the special notebook. This software is helpful for students who have a hard time listening and writing at the same time, so they may miss some of what is said. The pen records it and then they can fill in missing blanks by listening to the recordings at a later date.

In the future as an elementary teacher, I will take careful consideration to identify students' individual needs, and I will work hard to implement the use of appropriate assistive technologies. I think that education about the assistive technologies that are available and also how to use them is extremely important for teachers, parents, and students. I will want to make 
sure that I know lots about different assistive technologies, and be sure that I can implement them in my elementary classroom in beneficial ways for my students.

\section{Resources}

Cobb, A. (2011). Assistive technology: Enhancing the life skills of students with learning disabilities. Distance Learning, 8(4), 47-57

Forgrave, K. E. (2002). Assistive technology: Empowering students with learning disabilities. The Clearing House, 75(3), 122-126. doi:10.1080/00098650209599250

Livescribe Inc. (2013). Echo Smartpen. Available online at: http://www.livescribe.com/en- us/smartpen/echo/

Nuance Communications Inc. (2014). Dragon Naturally Speaking Software. Available online at: http://www.nuance.com/dragon/index.htm

Siglin, J. A. (2000). Play attention ${ }^{\circledR}$ on success. Intervention in School and Clinic, 36(2), 122124. doi:10.1177/105345120003600209

Texthelp. (2014). Read and Write Gold Software. Available online at: http://www.texthelp.com/north-america/our-products/readwrite

Word Q. (2011). Word Q Software. Available online at: http://www.goqsoftware.com 